\title{
Evaluation of Settlement and Bearing Capacity of Embankment on Soft Soil With Reinforced Geogrids
}

\author{
Entidhar T. Al-Taie ${ }^{1}$ \\ Department of Reconstruction and Projects \\ Ministry of Higher Education and Scientific Research \\ Baghdad / Iraq
}

\author{
Hala H. Al-Kalali ${ }^{2}$ \\ National Center for Engineering \\ Ministry of Construction and Housing \\ Baghdad / Iraq
}

\author{
Mohammed Y. Fattah ${ }^{3}$ \\ Building and Construction Department \\ University of Technology \\ Baghdad / Iraq
}

\begin{abstract}
The growth of population around the world requires establishment of many projects. For that, different techniques were established to improve the soft soil lands. One of the most widely used techniques for improving soft soil is the stone columns. In this paper, the work is conducted depending on the laboratory test for the soft soil reinforced with ordinary stone columns beneath embankment model. Analysis was done using Plaxis 3D finite element program to evaluate the settlement and bearing capacity and improving the soft soil beneath the embankment. The analysis was done for two cases with the condition of length to diameter of stone columns $\mathrm{L} / \mathrm{d}=$ 8. The first case was using one and two horizontal geogrid layers in the embankment at $0.5 \mathrm{~h}$ and $0.67 \mathrm{~h}$ compared to the case of without using of the horizontal geogrids layers, for different numbers of ordinary stone columns OSCs (seven, eight and nine). The second case used the same number of geogrid layers and OSCs with different applied loads $(10,15$ and 20$) \mathrm{kN}$. The results obtained from the first case reduced the settlement for the seven $5 \%$ and $9 \%$ and $11 \%$ for eight and nine, OSCs respectively, compared to the case of without used of geogrid layers for the same numbers of OSCs. For the second case, the reduction of settlement which leads to increase in bearing capacity influenced in the use of two horizontal geogrid layers for the load of $20 \mathrm{kN}$ by $29 \%, 16 \%$ and $18 \%$ for seven, eight and nine OSCs, respectively.
\end{abstract}

Keywords-: Soft soil, embankment, stone columns, geogrid layers, settlement, incremental loads.

\section{INTRODUCTION}

One of the most widely used techniques for improving soft soil is the stone columns "Fig. 1". Wide world areas are occupied by soft clay deposits. The growth of population around the world requires needing to establishment of many projects. Infrastructure projects such as roads and railways embankments, large storage tanks, factories, etc. require implementation wide areas, even if the areas contain soft soil. For that, different techniques were established to improve the soft soil lands such as: treating by dewatering, changing the upper layers of soft soil, using mini piles, used additives, used stone columns with or without reinforcement, etc. Stone columns are the most improvement technique used, to reduce the settlement and increase the bearing capacity of soft soil [1] [2] and [3].

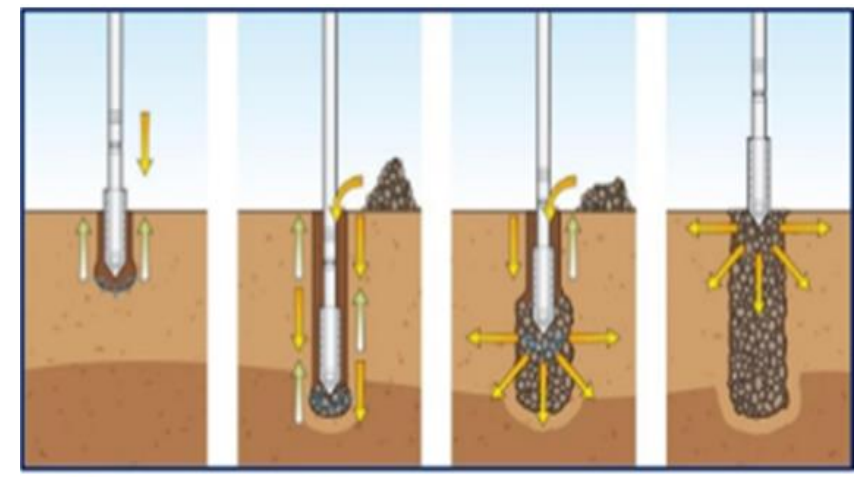

Fig. 1. stone columns [4]

The first time had been used stone columns techniques were in France at 1830. The stone columns are installed in different shapes such as square, triangular or hexagonal [5]. Since that time till now many developments had been done to use the stone columns technique efficiently.

Many developments had been done by different researchers (laboratory and filed works) to improve this technique since that time till now. Geotechnical designers preferred numerical analysis due to the availability of finite element codes and increasing in computer power. For that, a lot of numerical analysis was done, such as:

[6] Used encased stone columns (geosynthetics) to improving soft soil. The researchers examined the effect of geosynthetics encased columns diameters and different length during loading. The study showed that increased diameter of sand column will increased the performance of them.

[1] studied the contribution of geotextile encased sand columns (GESC) to global and vertical stability. The tests were done for three diameters: 10, 15, and $30 \mathrm{~cm}$ for both ordinary and geotextile sand columns.

[7] Studied the influence of sand columns encased by geosynthetics to improve strength property of black cotton soil. Sand columns were found useful to reduce settlement and load capacity of clay. Also they studied the influence of encased geosynthetics for different length and diameter of 
sand columns. The results showed that an increased in diameter and length of group of sand columns will give better results.

[8] Research was focused on improving the property of soft soil by using stone columns. By studying the effect of stone columns lengths and diameters on soft soil settlement and bearing capacity. The methodology used was the response surface. Using PLAXIS 2D for numerical modeling results showed that increase the stone columns diameters caused increased in load capacity. Also, when length columns increased will decrease in the settlement. For that, the optimum stone column design was change with diameter and length factors separately for improvement.

[9] Focused on the comparing between the effect of using stone columns with and without geogrids. The study had been done experimentally and numerical analysis using PLAXIS 3D. The results from both test and numerically showed that using stone columns with geogrids are the best solution to reduce settlement. Also, increase load bearing capacity comparing with the stone columns without geogrids by $60 \%$ and $20 \%$ respectively.

Moreover, [10] was working to show that the effectiveness of a simplified design approach against a laboratory test and field study. The method was sufficiently accurate in predicated the stone columns drained settlement. The researcher was using a simplified approach comparing with the field study and the laboratory test.

The aim of this research is to evaluate the settlement and bearing capacity for soft soil with the ordinary stone columns (OSCs) under reinforced embankment without and with one and two horizontal layers of geogrids. The evaluation is done by using numerical analysis (PLAXIS 3D) to find the effect of reinforcement geogrid layers in the embankment on the properties for soft soil beneath it. The physical and chemical properties of the crushed stones, natural soil, sub-base and geogrids used in the analysis were depended on the experimental work done by [5] [11] [12] and [13].

\section{METHODS}

The work was done by using finite element programme, depending on experimental data, as following:

\section{A. PLAXIS 3D program}

Plaxis $3 \mathrm{D}$ is a numerical program depend on a powerful tool is finite element, which is used to conducted analysis for stability, deformation and ground water flow for a different geotechnical implementation types. In another words it is used for complex engineering analysis problems. The program used for calculating static and dynamic models. For that, the program needs advanced constitutive models for the simulation of time-dependent, anisotropic and non-linear elastoplastic behaviour of soils and rocks. Also, this program enables to quickly generate of a model mush and geometry [14] and [15].

The program was used to simulate the experimental work and complex geotechnical problems, find the effected of settlement or slop stability [16]. Moreover, the program allows assigning soil properties to each layer of the soil geometry. For accuracy, the program improves the mush around points of great changes. In addition, the other boundary conditions such as flow of pore water, vertical and horizontal movements are used. For perfect drain, the program let zero lines of excess pore pressure to be added to the design [17]. The program adopted several material models such as Mohr coulomb, Linear isotropic elasticity, Hardening-soil, etc. Mohr Coulomb model (MC) is elastic perfectly plastic to implement the model must define the fallowing parameters: shear strength $\mathrm{c}$, internal friction angle $\phi$, Poisson's ratio $v$, Modulus of elasticity Es, and Angle of Dilatancy $\psi$. It is suitable to get early deformations assessment [16].

\section{B. Experimental Work}

A model for soft soil under embankment with stone columns was conducted in the laboratory by [5]. The soft clay soil was conducted by [5] as foundation with dimensions $1500 \mathrm{~mm}$ in $\mathrm{x}$-direction, $800 \mathrm{~mm}$ in y-direction and $560 \mathrm{~mm}$ in $\mathrm{z}$-direction and with $10 \mathrm{kPa}$ undrained shear strength. While, a sub-base granular material of 200 $\mathrm{mm}$ in y-direction with 1:1.5 side slope conducted as an embankment over the soft clay soil. Ordinary stone columns (OSCs) were used to reinforced the soft soil with diameter of $70 \mathrm{~mm}$ and with length-to-diameter ratio $(\mathrm{L} / \mathrm{d})$ $=8$. The space between columns was equal to $(2.5 \mathrm{~d})$ diameters. A footing with dimensions $(250 * 500) \mathrm{mm}$ for applied load was placed on the embankment surface [5] [11] [12] and [13].

Table I shows the physical properties for soft soil, granular sub-base (which is usually used as fill material for construction of embankment) and crushed stone which is used to implement stone columns. Also, the mechanical properties of the geogrid material used in the reinforcement of embankment were provided by [5] and [13]. Yield strength value used was $0.47 \mathrm{kN} / \mathrm{m}$ and the value of the tensile modulus used was $79 \mathrm{kN} / \mathrm{m}$ as illustrated in Table II.

Table I. Physical properties for materials used in the model [13].

\begin{tabular}{|c|c|c|c|c|}
\hline Parameter & $\begin{array}{c}\text { Soft } \\
\text { soil }\end{array}$ & $\begin{array}{c}\text { Sub- } \\
\text { base }\end{array}$ & $\begin{array}{c}\text { Crushed } \\
\text { stone }\end{array}$ & Unit \\
\hline $\begin{array}{c}\text { Total unit weight } \\
\boldsymbol{\gamma}_{\boldsymbol{t}}\end{array}$ & 18.85 & 24.22 & - & $\mathrm{kN} / \mathrm{m}^{3}$ \\
\hline $\begin{array}{c}\text { Dry unit weight } \\
\boldsymbol{\gamma}_{\boldsymbol{d}}\end{array}$ & 13.24 & 21.84 & 15.7 & $\mathrm{kN} / \mathrm{m}^{3}$ \\
\hline $\begin{array}{c}\text { Internal friction angle } \\
\boldsymbol{\phi}\end{array}$ & 0 & 40 & 41.5 & $\mathrm{Degrees}$ \\
\hline $\begin{array}{c}\text { Undrained shear } \\
\text { strength } \boldsymbol{C} \boldsymbol{u}\end{array}$ & 10 & 0 & 0 & $\mathrm{kPa}$ \\
\hline $\begin{array}{c}\text { Poisson's ratio } \\
\boldsymbol{v}\end{array}$ & 0.45 & 0.3 & 0.3 & - \\
\hline $\begin{array}{c}\text { Elastic modulus } \\
\mathbf{E}_{\mathbf{s}}\end{array}$ & 2000 & 100 & 100000 & $\mathrm{kPa}$ \\
\hline $\begin{array}{c}\text { Coefficient of } \\
\text { permeability } \boldsymbol{k}\end{array}$ & 0.0212 & 20 & - & $\mathrm{m} / \mathrm{d}$ \\
\hline
\end{tabular}

Table II. Mechanical properties of the geogrid [13].

\begin{tabular}{|c|c|c|}
\hline Parameter & Geogrid & Unit \\
\hline Elastic modulus $\boldsymbol{E}_{\boldsymbol{s}}$ & 400000 & $\mathrm{kPa}$ \\
\hline Rib thickness & 1.7 & $\mathrm{~mm}$ \\
\hline Tensile strength & 0.44 & $\mathrm{MPa}$ \\
\hline Elongation & 1.4 & $\%$ \\
\hline
\end{tabular}

\section{The model}

The parameters illustrated in Tables I and II respectively are used to build the constitutive the model in the PLAXIS 
3D program. Mohr Coulomb constitutive model (MC) was chosen for the analysis of the stress-strain behavior for the reinforce soil with stone column and the embankment above it. Halve of the embankment was modeled due to symmetry, and for saving the time of computation as shown in Fig. 2 and 3. The dimensions of the soft soil model adopted by [5] are $(1500 * 800 * 560) \mathrm{mm}$ in $\mathrm{X}, \mathrm{Y}$ and $\mathrm{Z}$ directions, respectively. Ordinary stone columns were modeled with length equal to 8 (L/d). While, embankment dimensions are $300 \mathrm{~mm}$ in $\mathrm{X}$ direction, $600 \mathrm{~mm}$ in $\mathrm{Y}$ direction and $200 \mathrm{~mm}$ in $\mathrm{Z}$ direction. Analysis was done for different numbers of stone columns: seven, eight and nine. Also the horizontal geogrid layers were taken in the embankment in two cases.

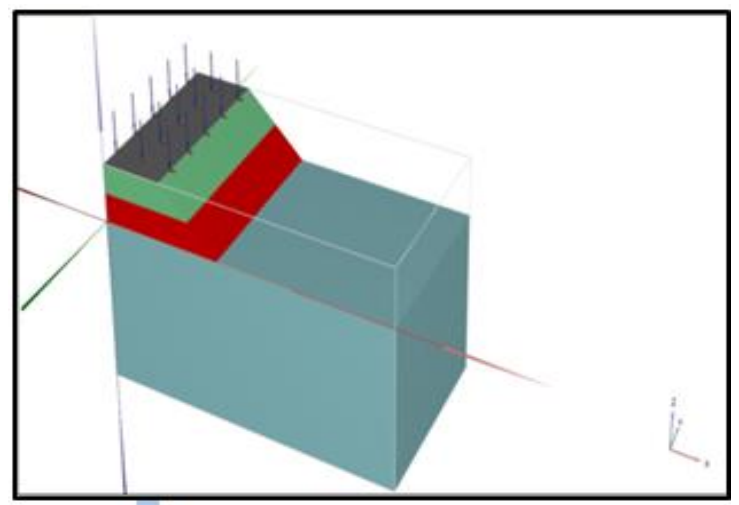

Fig. 2. Halve of the embankment in 3D analysis.

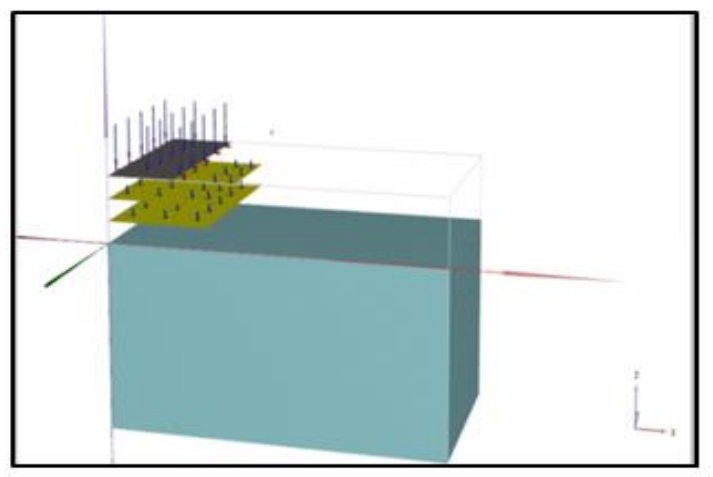

Fig. 3. Embankment model with 2 layers geogrid.

In the first case the geogrid layer was inserted at 0.5 heights $(h)$ of the embankment, where $h$ is the height of embankment. While, in the second case, two layers of geogrid were used at $0.67 \mathrm{~h}$ of the embankment. The program analyses are conducted for any soil problem in five steps. First step is definition of soil stratigraphy with material data sets; second step is definition of elements of structural. Generation of the mesh for the model is done automatically in the third step (Fig. 4). In the fourth step, the water level is located. The last step is performing calculations.

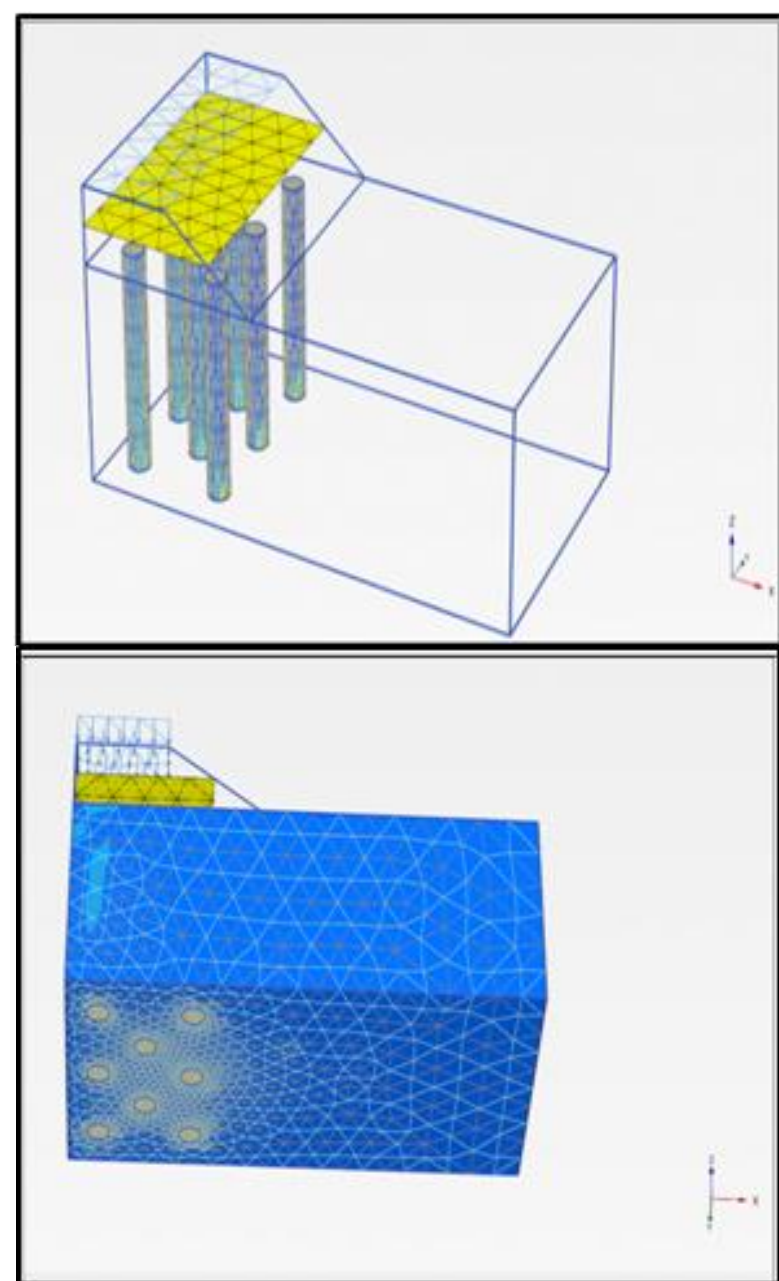

Fig. 4. Embankment with reinforced stone columns finite element mesh for the model.

\section{RESULTS AND DISCUSSION}

The analysis was done using PLAXIS 3D for the embankment model established on soft soil reinforced with ordinary stone columns (OSCs).

\section{A. Settlement}

Analysis was done for models with different numbers of OSCs with and without using of horizontal geogrid layers in the embankment. In the first case, the analysis was done for seven, eight and nine OSCs without using of geogrid layers in the embankment. While, used of one horizontal layer of geogrid at a $0.5 \mathrm{~h}$ (height) of the embankment as a second case. The third case included embedment of two horizontal geogrid layers at $0.67 \mathrm{~h}$ for seven, eight and nine OSCs, respectively. The finite element results are illustrated in Fig. 5 for the comparison between the three cases mentioned above. 


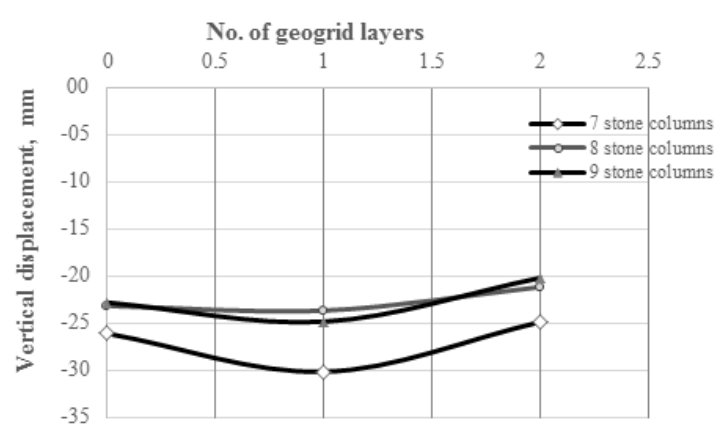

Fig. 5. Relation between vertical displacement verses No. of geogrid layers.

Fig. 5 shows the settlement or vertical displacement plotted against number of horizontal geogrid layers for the soft soil beneath the embankment model embedded at $0.5 \mathrm{~h}$ in one case and $0.67 \mathrm{~h}$ for the other case. The displacement is calculated at nodes 535, 322 and 2373, respectively shown in Figure 4. Also, the analysis was done for the case without horizontal geogrids layers for the seven, eight and nine OSCs. The curves illustrate reducing in the settlement in the rate of 5 $\%$ for the two cases compared to the case of without geogrid layers for seven OSCs. While, when using eight OSCs for the two cases, the settlement reduced 9\% compared without geogrid layers and $11 \%$ for the nine OSCs. The use of the horizontal geogrid layers improved the soft soil under the embankment. This means that the use of the horizontal geogrid layers at $(0.5 \mathrm{~h}$ and $0.67 \mathrm{~h})$ is an effective way for improving the soft soil. The values of settlement as shown in Fig. 5 show that the soft soil improved for the eight and nine OSCs with two layers of geogrid more than for the seven OSCs with two layers of geogrid.

\section{B. Bearing Capacity}

In this research, the laboratory works and the numerical analysis done by [5] and [13] were analysed for the model of soft soil treated with OSCs beneath embankment using PLAXIS 3D. The plotted area is illustrated in Fig. 6. This is between the load increments $(10,15$ and 20) $\mathrm{kN}$ and the settlement for the treated soft soil with seven OSCs beneath the embankment without and with one and two horizontal geogrids.

The results show that settlement is reduced but not with great value, only in the case of using two horizontal geogrid layers. For that, the ultimate bearing capacity is considered via the failure load according to a settlement that represents $10 \%$ of footing width. Using of the two horizontal geogrid layers with the seven OSCs is more effective than the other two cases for the same number of OSCs.

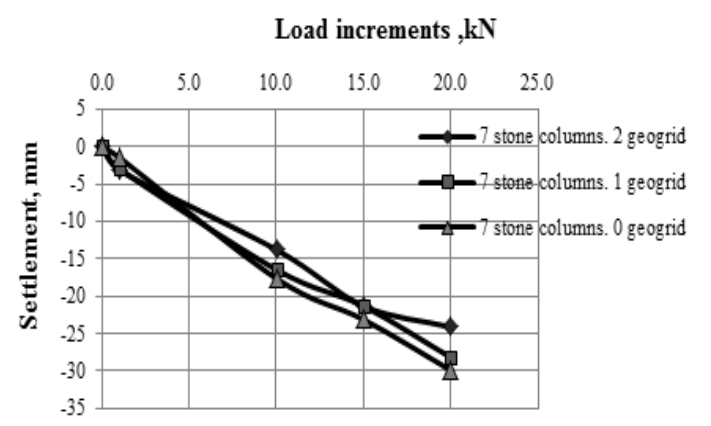

Fig. 6. Settlement verses load increments for seven OSCs with and without reinforcement in the embankment.

Fig. 7 illustrates the relation between the settlement versus load increments $(10,15$ and 20$) \mathrm{kN}$. The results are for the eight OSCs without and with one and two horizontal geogrid layers. The use of the horizontal geogrid layers improved the soft soil by obtaining a major reduction in the settlement. which leads to a maior increase in the bearing

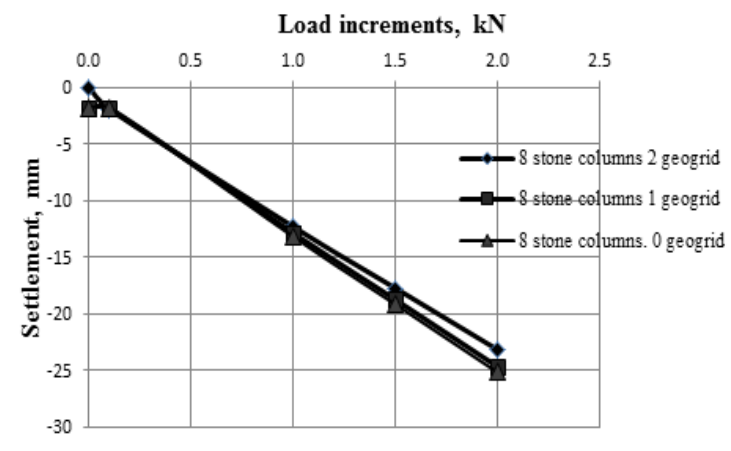

Fig.7. Settlement verses load increments for eight OSCs with and without reinforcement in the embankment.

While, Fig. 8 illustrates the results using the same criterion for the load and the geogrid layers for soil treated with nine OSCs. The two horizontal geogrid layers cause major reduction in settlement, which affected the major increase in bearing capacity, especially in the case when using of two geogrid layers as shown in Fig. 8. The analysis was done by the program shows that the use of two horizontal geogrid layers with nine OSCs is more effective in improving the soft soil bearing capacity.

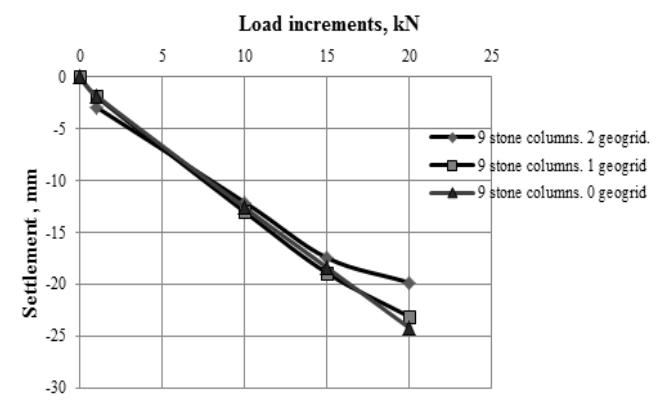

Fig. 8. Settlement verses load increment for nine OSCs with and without reinforcement in the embankment.

Results obtained from the finite element analysis show the influence of the using of two horizontal geogrid layers for the 
seven, eight and nine OSCs are effective in reducing the settlement with the load applied of $20 \mathrm{kN}$. The comparison is shown in Table III.

TABLE III. THE PERCENTAGE REDUCTION OF SETTLEMENT UNDER A LOAD OF $20 \mathrm{KN}$.

\begin{tabular}{|c|c|c|}
\hline $\begin{array}{c}\text { No. of stone } \\
\text { columns }\end{array}$ & $\begin{array}{c}\text { One geogrid } \\
\text { layer }\end{array}$ & $\begin{array}{c}\text { Two geogrid } \\
\text { layers }\end{array}$ \\
\hline 7 & $6 \%$ & $29 \%$ \\
\hline 8 & $10 \%$ & $16 \%$ \\
\hline 9 & $5 \%$ & $18 \%$ \\
\hline
\end{tabular}

The results in Table 3 show that the use of two geogrid layers is effective especially for the seven OSCs.

\section{CONCLUSIONS}

The work of this paper was implemented depending on the experimental model for the embankment over reinforced soft soil with ordinary stone columns; the work was done by [5]. The important points get from this research are:

- The use of the horizontal geogrid layers in the embankment reduced the settlement in the rate of $6 \%$ for the seven OSCs and 9\%, 11\% for the eight and nine OSCs, respectively.

- The value of settlement was reduced for all cases with load increments and did not exceed the failure criterion of $10 \%$ of footing width, which means that the ultimate bearing capacity was increased.

- The more using of horizontal geogrids layers with OSCs will improve the soft soil. The reduction in settlement for the two geogrid layers for the seven, eight and nine OSCs for the load value of $20 \mathrm{kN}$ is $29 \%, 16 \%$ and $18 \%$, respectively.

\section{REFERENCES}

[1] Sh.T. Kadhim, "Stability analysis of geotextile encased sand column" Ph.D. Thesis, Department of Civil, Environmental, and Architectural Engineering, University of Kansas, 2016, USA.

[2] S.Z.M. Al- Saadi, "Soil improvement by using granular column with additives" Ph.D. thesis, College of Engineering, University of Baghdad, 2017, Iraq.

[3] A.K.. Ahmed Naseem and K. A. Patil (2018), Geo reinforced stone column technique for soft clay soil improvement - A review' International Journal of Engineering Sciences \&Research Technology, Vol. 7, No. 4, Aprail, 2018, pp 68-76. www.ijesrt.com
[4] Pathariya ,S. (2016) Stone column, https://www.slideshare.net/SARASWATIPATHARIYA/stone-columntheory-applications

[5] H. A. Hassan, " An experimental and theoretical study on ordinary and encased stone columns underneath embankment " Ph.D. thesis, College of Engineering, University of Baghdad, 2013, Iraq.

[6] U. Kumar, Y. K. Tandel, and C. H. Solanki "Effect of geosynthetic encasement on sand column in soft soil" International Journal of Structural and Civil Engineering Research, Vol. 2, No. 3, 2013, pp141146.

[7] C. Harish, M. S. Nagaraja Gupta, K. N. Radhik and Manjunathltagi" Effect of sand column with and without encasement of geosynthetics in black cotton soil" International Research Journal of Engineering and Technology, Vol. 3, No. 7, 2016, pp765-2071.

[8] A. Madun, S. A. Meghzili, S.A.A.Tajudin, M.F. Yusof, M.H Zainalabidin, A.A. Al-Gheethi, M.F. Md Dan and M.A.M Ismail." Mathematical solution of the stone column effect on the load bearing capacity and settlement using numerical analysis" IOP Conf. Series: Journal of Physics: Conf. Series 995, IOP Publishing, 2017, ISMAP.

[9] S.F. Kawa, E.S. Kolosov, and M.Y. Fattah" Ground improvement using stone column construction encased with geogrid" Construction of Unique Buildings and Structures, 2018, Vol. 66, No.3, pp 49-59.

[10] K.Sh. $\mathrm{Ng}$ "Prediction of drained settlement and ultimate bearing capacity for stone columns supported foundation" International Congress and Exhibition, Sustainable Civil Infrastructures: Innovative Infrastructure Geotechnology, Soil Testing, Soil Stability and Ground Improvement, Springer International Publishing, 2018, pp12-19.

[11] M.Y. Fattah, B.S. Zabar and Hassan H.A. Hassan " An experimental analysis of embankment on stone columns" Journal of Engineering, University of Baghdad, 2014, Iraq, Vol. 20, No.7, pp 62-84.

[12] M.Y.Fattah, Zabar B.S. Zabar, and H.A. Hassan "Soil arching analysis in embankments on soft clays reinforced by stone columns" Structural Engineering and Mechanics, 2015, Vol. 56, No.4, pp 507-534.

[13] Fattah M.Y. Fattah, H.A. Mohammed and H.A. Hassan " Load transfer and arching analysis in reinforced embankment, structures and Buildings" Proceedings of the Institution of Civil Engineers, 2016, 169,Issue SB11, pp797-808.

[14] R. B. J. Brinkgreve, E. Engin and W. M. Swolfs editors "PLAXIS 3D" 2013, Material Manual.

[15] N. Nehab, K. Baha, L. Ouadif and L. Bahi (2016) "Three- dimensional of a group of stone columns in "Bourgreg valley" soft ground" Journal of Engineering and Applied Sciences, Asian Research Publishing Network (ARPN), 2016, Vol. 11, No. 24, pp14537-14544. www.arpnjournals.com

[16] B. Gunduz "Analysis of settlements of test embankment during 50 years- a comparison between field measurement and numerical analysis" Master thesis, printed by KFS Lund AB, Lund University, 2010, Sweden. www.byggmek.1th.se

[17] J. Montgomery and M. Karstunen "Modelling embankment with vertical drains-a comparison of numerical methods" 17 th International Conference on Soil Mechanics and Geotechnical Engineering, ISO press, 2009, Germany, pp 161-1613. 